Article

\title{
Atomistic Simulations and Experimental Investigations of the Diffusion Behavior of Steel/ZCuPb20Sn5 Bimetals
}

\author{
Mingjie Wang, Guowei Zhang, Hong $X u$ * and Yufei Zhang \\ School of Materials Science and Engineering, North University of China, Taiyuan 030051, China; \\ 15513882577@163.com (M.W.); zhangguowei@nuc.edu.cn (G.Z.); s1703010@stu.nuc.edu.cn (Y.Z.) \\ * Correspondence: xuhong@nuc.edu.cn; Tel.: +86-0351-3922751
}

Received: 8 May 2020; Accepted: 3 June 2020; Published: 8 June 2020

check for updates

\begin{abstract}
A hybrid verification method consisting of experiments and molecular dynamics simulations was implemented to investigate the diffusion behaviour of steel/ZCuPb20Sn5 bimetals. The effects of different carbon steels (Q235 steel, 45 steel, and T8 steel), pouring temperatures, and holding times on their microstructures and mechanical properties were studied to obtain the optimum process parameters. The experimental results indicated that the pouring temperature and holding time played an imperative role in improving the shear strength of the steel/copper bimetallic composite. The highest bonding strength of all the steel/copper bimetallic composites was obtained at $1523 \mathrm{~K}$ and the holding time of $40 \mathrm{~min}$. Moreover, the carbon steel of 45 steel with a ZCuPb20Sn5 interface exhibited the highest bonding strength because of the appropriate pearlite content along with the preferable structure and micro-hardness for the considered diffusion width and bonding strength. Meanwhile, the diffusion distance of copper atoms in the carbon steel matrix was smaller than that of iron atoms in the $\mathrm{ZCuPb} 20 \mathrm{Sn} 5$ matrix. In the simulation results, the diffusion coefficient of $\mathrm{Cu}$ atoms was smaller than that of Fe atoms, but the diffusion distance of Fe atoms in the Cu bulk was larger than that of $\mathrm{Cu}$ atoms in the Fe bulk; this showed a significant agreement with the experimental result.
\end{abstract}

Keywords: steel/copper bimetal; optimum process parameters; molecular dynamics simulation; microstructure; mechanical properties

\section{Introduction}

Bimetallic-bonding compound materials join two types of metals by using different methods [1,2] which combine the excellent performance of the metals used and considerably improve the properties of strength, hardness, and wear resistance [3,4]. As one of the best engineering materials, iron-copper bimetals play an important role in many industries [5,6], particularly in aerospace and pump construction, because of their high bonding strength and good wear resistance [7,8]. For instance, a plunger pump rotor as a typical iron-copper bimetal with a high rigidity and wear resistance requires excellent performance for the working surface, such as a small coefficient of friction, high wear resistance, and excellent thermal conductivity and fatigue performance; thus, the high lead-copper-tin bronzes are selected to lubricate the working surface $[9,10]$. Thus far, a study on the joint between a carbon steel and a copper alloy has been of great interest.

There are many methods to fabricate copper/steel bimetals, such as explode welding [11], friction welding [12,13], laser welding [14,15], powder metallurgy [16-18], squeeze casting [19], induction cladding [20,21], and transient liquid phase [22-24]. In general, welding and induction cladding are used conventionally. However, they are mainly applied in components with a regular interface, and it is difficult to produce complex bimetallic components with an inner cavity. Moreover, the bonding strength 
of the interface for the steel/copper bimetals fabricated by welding and induction cladding is in the range of 70-140 MPa [19,25], which hardly meets the strength requirements under poor working conditions. Similarly, powder metallurgy is an energy-saving, high-efficiency, and environment-friendly method to manufacture bimetals, but it is difficult to guarantee a high bonding strength, which is in the range of 90-130 MPa in other reports $[17,26]$. The squeeze casting and transient liquid phase method can slightly improve the diffusion bonding and formation of the bimetallic materials. However, it is difficult to apply this method widely because of its relatively low bonding strength.

$\mathrm{Fe}-\mathrm{Cu}$ bimetals have always been used in complex high-voltage and high-power environments, which require a high bonding strength and good performance. However, as a bimetallic formation method, powder metallurgy can hardly produce complex structural components. The bonding strength of Fe-Cu bimetals fabricated using a conventional solid-liquid forming method does not usually meet the working requirement. While the solid-liquid forming method using the melting borax protection technology can increase the bonding strength and diffusion thickness of the interface by improving the diffusion rate of the interfacial atoms, it has been reported that the metallurgical bonding and diffusion bonding at the interface are better than the physical bonding [27-34]. In contrast, the value of the bonding strength can not only be determined by the thickness of the interface but also be influenced by the interfacial structure. Therefore, it is necessary to determine the internal relation between the diffusion thickness, structure, and bonding strength.

Recently, molecular dynamics has been the most commonly used molecular simulation method. When an atom or molecule is in a force field, it moves according to Newtonian mechanics. Thus, the macroscopic properties of the system can be obtained. This method can be widely used to simulate different nano-scale properties without the limitation of the sample preparation and the test conditions. Therefore, on the basis of molecular dynamics, we have used this method to study the distribution of different atoms at the interface of $\mathrm{Fe} / \mathrm{Cu}$ bimetallic systems, which provides a theoretical basis for the accuracy of the experimental results.

In this study, the mean square displacement, interfacial atomic concentration, and radial distribution function of the $\mathrm{Fe} / \mathrm{Cu}$ interface were calculated to improve the experimental results. The Q235 steel, 45 steel, and T8 steel were bonded with a high lead-copper alloy using compound casting. The influences of the steels' structures, pouring temperatures, and holding times on the diffusion distance, microstructure, and mechanical properties of the steel/copper bimetals were investigated. The comparative interface bonding properties and the diffusion distance of ferrite, pearlite, and cementite between the steel and copper bimetallic composites were also characterised and analysed.

\section{Methods}

\subsection{Simulation Methodology}

All the molecular dynamics simulation calculations were implemented using the large-scale atomic molecular massively parallel simulator (LAMMPS) [35] with time steps of $2.0 \mathrm{fs}$. In the MD simulation, the inter-atomic potentials describing the potential energy of the atoms playing a pivotal function. The embedded atomic method (EAM) potential developed by Bonny et al. [36], which has thus far been used for exploring diffusion properties, was used for modelling the atomic interaction of $\mathrm{Fe}-\mathrm{Cu}$ bimetallic atoms [37] and the mechanical properties [38] of $\mathrm{Fe}-\mathrm{Cu}$ alloys. Moreover, the Nose-Hoover thermostat (D.J. Evans, Canberra, Australia) was used, and periodic boundary conditions were applied in the two transverse ( $x$ and $y$ ) directions.

Considering the simulation temperature and the $\mathrm{Fe} / \mathrm{Cu}$ interface structure to be at a relatively high temperature, fcc Fe and fcc $\mathrm{Cu}$, with a lattice constant of $0.3658 \mathrm{~nm}$ and $0.36147 \mathrm{~nm}$, respectively, were selected to construct the $\mathrm{Fe} / \mathrm{Cu}$ interface model at $1523 \mathrm{~K}$. Moreover, the Fe/Cu cubic super-cells were constructed, wherein the Fe cubic super-cells were $10 \times 5 \times 60$ and the $\mathrm{Cu}$ cubic super-cells were $10 \times 5 \times 60$ because of the different lattice constants of $\mathrm{Fe}$ and $\mathrm{Cu}$. Moreover, the $\mathrm{Fe} / \mathrm{Cu}$ was first relaxed at equilibrium under the constant pressure and temperature (NPT) ensemble for $200 \mathrm{ps}$, then the 
temperature was increased to $1523 \mathrm{~K}$ rapidly. Thereafter, the Fe/ $\mathrm{Cu}$ interface model was maintained for 1000 ps at $1523 \mathrm{~K}$, and all the diffusion information of the $\mathrm{Fe}$ and $\mathrm{Cu}$ atoms was recorded in this process. Although the EAM model provides a realistic description of the dynamics of solid surfaces $[39,40]$ and the bulk [41,42], the predicted properties need to be verified by the first principles MD simulations (for relatively small super-cell sizes) at different temperatures [43-45].

\subsection{Experimental Materials}

The experiment materials used were the ZCuPb20Sn5 copper alloy and the carbon steels of Q235 steel, 45 steel, and T8 steel, which are usually used in plunger pump rotors with high lead-tin-bronze; the chemical compositions of the alloys are shown in Tables 1 and 2. The carbon steel and the $\mathrm{ZCuPb} 20 \mathrm{Sn} 5$ copper alloy were applied as the substrate and the melting copper bath, respectively. The cylindrical cavity steel mould was machined from a carbon steel. Figure 1 shows the shape and the size of the mould. Before the pre-heating treatment of the carbon steel, the internal surface was ground by silicon carbide papers and then rinsed with hydrochloric acid $(10 \% \mathrm{HCl})$, sodium hydroxide $(10 \% \mathrm{NaOH})$, and absolute ethyl alcohol.

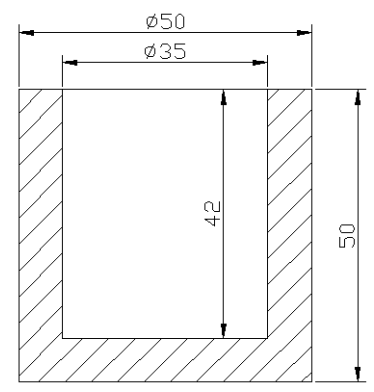

Figure 1. Shape and dimensions of the steel mould.

Table 1. Chemical compositions of the carbon steels (wt.\%).

\begin{tabular}{ccccccccc}
\hline \multirow{2}{*}{ Alloys } & \multicolumn{8}{c}{ Elements (wt.\%) } \\
\cline { 2 - 9 } & $\mathbf{C}$ & Si & Mn & S & P & Ni & Cr & Fe \\
\hline Q235 steel & 0.18 & 0.02 & 0.45 & 0.035 & 0.035 & - & - & balance \\
45 steel & 0.45 & 0.25 & 0.62 & 0.025 & $\leq 0.025$ & 0.2 & 0.15 & balance \\
T8 steel & 0.81 & 0.30 & 0.30 & 0.015 & 0.02 & 0.15 & 0.15 & balance \\
\hline
\end{tabular}

Table 2. Chemical compositions of the ZCuPb20Sn5 copper alloy (wt.\%).

\begin{tabular}{ccccccc}
\hline Element & $\mathbf{C u}$ & $\mathbf{P b}$ & $\mathbf{Z n}$ & $\mathbf{S n}$ & $\mathbf{N i}$ & $\mathbf{P}$ \\
\hline Content & balance & 20.4 & 1.8 & 5.0 & 2.0 & 0.25 \\
\hline
\end{tabular}

\subsection{Casting Process}

The $\mathrm{ZCuPb} 20 \mathrm{Sn} 5$ copper alloy placed in a graphite crucible was melted in an electric resistance furnace and then kept on heat reservation when the heating temperature increased to 1100, 1200, and $1300^{\circ} \mathrm{C}$. Dehydration borax was placed on the steel substrate and pre-heated to $30^{\circ} \mathrm{C}$ for $2.5 \mathrm{~h}$ by using a rapid induction heating coil for complete dehydration. The Q235 steel, 45 steel, and T8 steel were pre-heated to $1200{ }^{\circ} \mathrm{C}$ in the melting borax bath for $20 \mathrm{~min}$, which could ensure sufficient pre-heating and avoid the oxidation of carbon steel at high temperatures. At the same time, insulated cotton was applied to maintain the temperature of the steel substrate. Subsequently, the preheated carbon steel was taken out and placed onto the insulated cotton, then the melted copper alloys were poured into the cylindrical cavity at 1100,1200 , and $1300{ }^{\circ} \mathrm{C}$. Thereafter, the steel substrate and the liquid copper alloy were kept at $1200^{\circ} \mathrm{C}$ for different holding times (10, 20, 30, 40, 50, 60, and 70 min). Figure 2 shows a schematic representation of the experimental process and the equipment. 


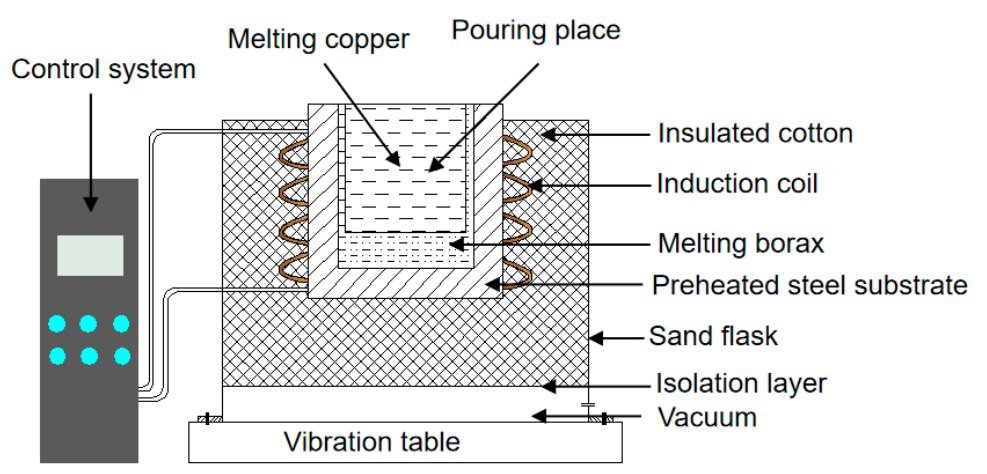

Figure 2. Schematic representation of the experimental equipment.

\subsection{Microscopy Methodology}

The metallographic specimens longitudinally cut from the middle were prepared to investigate the microstructure and the element distributions at the interface. The optical microscope (OM), SU5000 Hitachi's (Tokyo, Japan) thermal field emission scanning electron microscope (SEM), and X-ray spectroscopy (EDS) analyses were utilised to examine the microstructure and the intermetallic phase.

\subsection{Mechanical Properties}

An HV-1000 Vickers hardness tester (Laizhou Huayin Test Instrument Co., Ltd, Laizhou, China) was utilised to measure the micro-hardness of the interface of the steel/copper bimetal. The specimens were machined from the middle of the castings with a thickness of $10 \mathrm{~mm}$; the schematic representation is shown in Figure 3a. The test moulding and the measurement of the shear strength of the steel/copper bimetal are shown in Figure 3b. The steel support was passed through quenching with subsequent tempering in order to support the considerably large shear force. In addition, push-out tests were conducted using the ZwickZ100 universal hydraulic machine (Guangzhou, China) to push out the copper alloy inset. During the test, the maximum load $\left(F_{\max }\right)$ was obtained when the copper insert was pushed out through a steel cylinder stub punch at the rate of $0.5 \mathrm{~mm} / \mathrm{min}$, which was recorded for the further calculation of the shear strength $\left(\tau_{\text {int }}\right)$, according to the following equation:

This is an example of an equation:

$$
\tau_{\text {int }}=\frac{F_{\max }}{\pi r^{2} d}
$$

where $r$ denotes the radius of the punch and $\mathrm{d}$ represents the thickness of the copper insert and the steel base specimens.

(a)

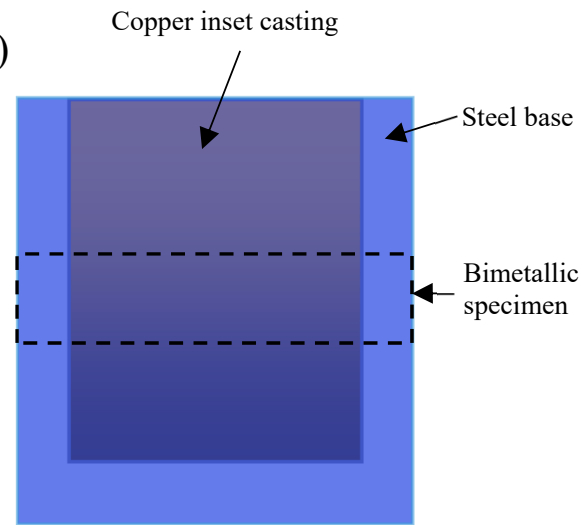

(b)

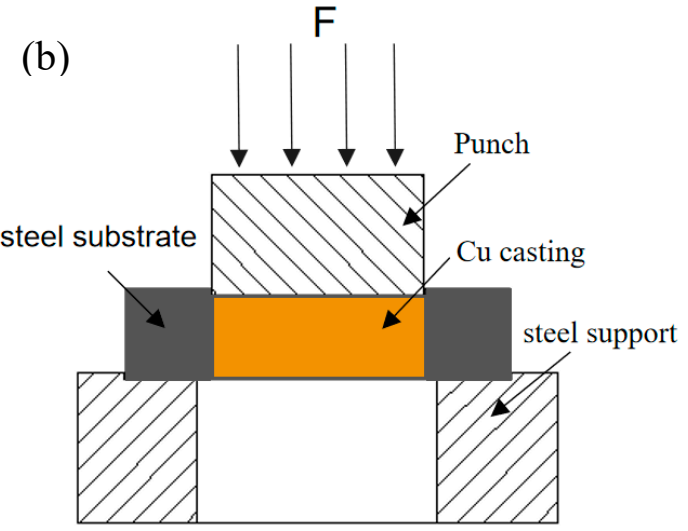

Figure 3. Schematic representation of the specimen location and shear equipment: (a) location of specimens and (b) testing process of the bimetallic shear strength. 


\section{Results and Discussion}

\subsection{Mechanical Characterisation}

Figure 4a presents the influence of the melting temperature of copper alloys on the shear strength of the bimetals. The 45 steel/copper bimetallic materials exhibited the maximum shear strength of $177 \mathrm{MPa}$ at the pouring temperature of $1250^{\circ} \mathrm{C}$, which might be attributed to the excellent bonding interface between the copper alloy and the steel. However, the maximum values for the Q235 steel/copper and T8 steel/copper were $155 \mathrm{MPa}$ and $168 \mathrm{MPa}$, respectively, indicating that the microstructure could evidently influence the interface's shear strength. Following the conformational analysis of the effectiveness of the matrix materials, it was necessary to assess the influences of the pouring temperatures. With the increasing temperatures, the interface bonding strength increased first because of the increasing thermal excitation, then the strength decreased because the grains grew larger at high temperatures [46]. The interface bonding strength as a function of the holding time is shown in Figure $4 \mathrm{~b}$. The same change regularity with the temperature increase revealed that the shear strength increased with the holding time before $40 \mathrm{~min}$ and then decreased with the extension of the holding time because of the coarse grain structure.
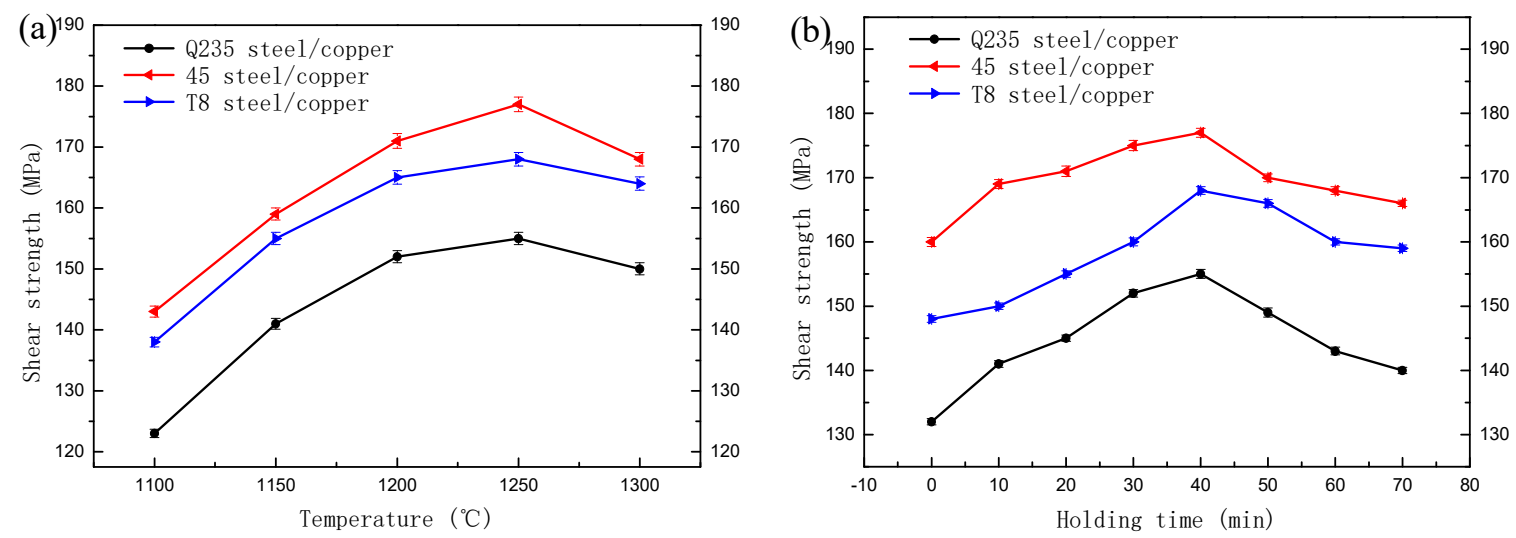

Figure 4. Shear strength of the steel and copper bimetallic casting at different temperatures and holding times in the solid-liquid compound casting process: (a) different temperatures and (b) different holding times.

\subsection{Molecular Dynamics Simulation Result}

As shown in Figure 5a, the Fe and $\mathrm{Cu}$ atoms of the bonded interface were well diffused into two prime bulks at $1523 \mathrm{~K}$, which represented the diffusion phenomena and regions at the Fe/Cu interface. In addition, the diffusion distance of the Fe atoms in the $\mathrm{Cu}$ bulk $(1.7 \mathrm{~nm})$ was larger than that of the $\mathrm{Cu}$ atoms $(0.7 \mathrm{~nm})$ in the Fe bulk within 1ns; this phenomenon can be clearly interpreted from Figure 5c. From Figure 5b, we calculated the mean square displacement (MSD) of the typical Fe and $\mathrm{Cu}$ atoms at $1523 \mathrm{~K}$; thus, the diffusion coefficient of the Fe and $\mathrm{Cu}$ atoms could be obtained by using the slope of the MSD curves. Careful observation showed that the diffusion coefficient of the Cu atoms at $1523 \mathrm{~K}$ was larger than that of the Fe atoms, but the diffusion distance of the Fe atoms was larger that of the $\mathrm{Cu}$ atoms; this agreed well with the viewpoint of the reference. Moreover, the comparison of the radial distribution function (RDF) of the $\mathrm{Fe} / \mathrm{Cu}$ interface and the pure Fe and $\mathrm{Cu}$ regions, as shown in Figure 5d, revealed that the first peak of the interface region became higher and narrower, indicating that the order degree and amount of bonding atoms at the interface had increased. 
(a)
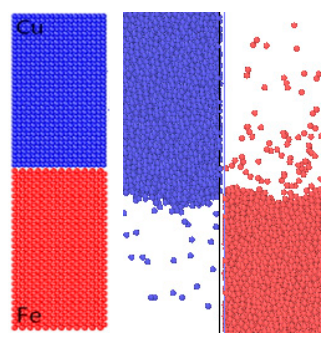

(c)

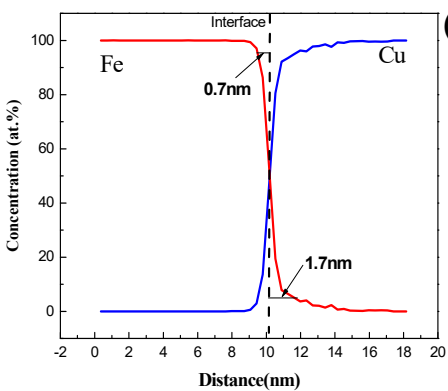

(b)

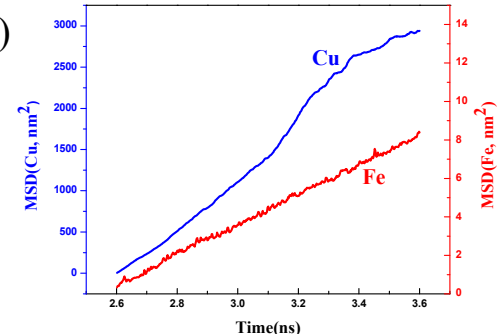

(d)

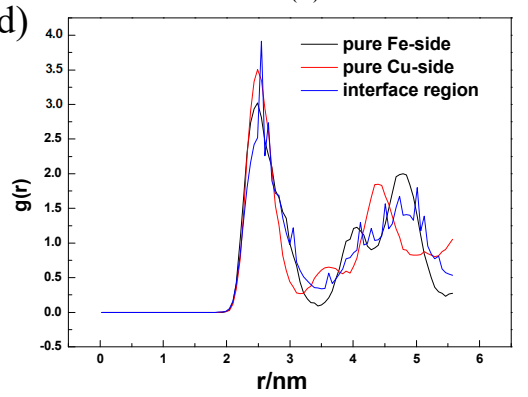

Figure 5. Molecular dynamics simulation results of the Fe/Cu interface: (a) initial model and optimised model, (b) mean square displacement (MSD) of the Fe and $\mathrm{Cu}$ side at $1523 \mathrm{~K}$, (c) concentration of the interface $\mathrm{Fe}$ and $\mathrm{Cu}$ atoms, and (d) radial distribution function (RDF) of the Fe/Cu interface at $1523 \mathrm{~K}$.

\subsection{Microstructure Characterization}

Figure 6 shows the SEM images and the EDS analysis of the steel/copper bimetals. It clearly shows that the microstructure of the interface was well integrated during the solid-liquid compound casting, indicating that the molten borax had a good effect on preventing the oxidation of the steel matrix at high temperatures. The interface of the steel/copper bimetals had uniform and compact metallurgical bonding layers, indicating that the outstanding performance of the steel/copper alloy bimetal was achieved through the instantaneous induction heating compound casting. As shown in Figure 6, the formation of the pro-eutectoid cementite held back the copper atoms from diffusing into the steel matrix, which explained the lower shear strength of the T8 steel/copper bimetal.
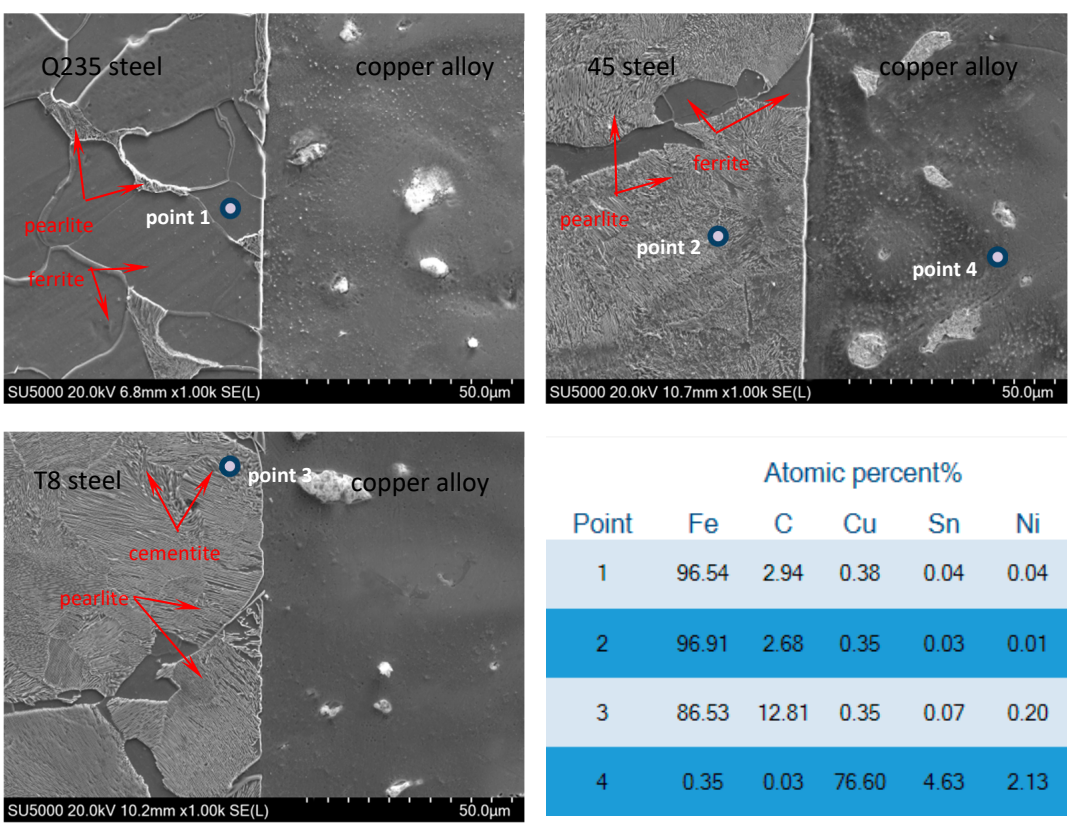

Figure 6. SEM micro-images and EDS point analyses of the interface microstructure of the steel/copper bimetallic castings using rapid induction heating. 
The 45 steel/copper bimetal was adopted to provide detailed illustrations of the diffusion behaviours between the steel (pearlite and ferrite) and the copper. An EDS point scan is an effective quantitative analysis method to obtain the concentration of various elements at different places which indicates the concentration change trend of the diffusion type. The main element concentrations around the interface were investigated; Figure 7a,b illustrates the trends of the concentrations of the copper and iron atoms in pearlite and ferrite, respectively. According to the EDS result, the diffusion region interface of steel and copper was composed of the $\mathrm{Cu}$ and Fe compounded elements and distributed in a gradient at the bimetallic interface. Therefore, we inferred that a metallurgical bonding interface was successfully established. As shown in Figure 6, the diffusion distance of the copper atoms in pearlite was larger than that in ferrite; this might be attributed to the different diffusivity values of the pearlite and ferrite.
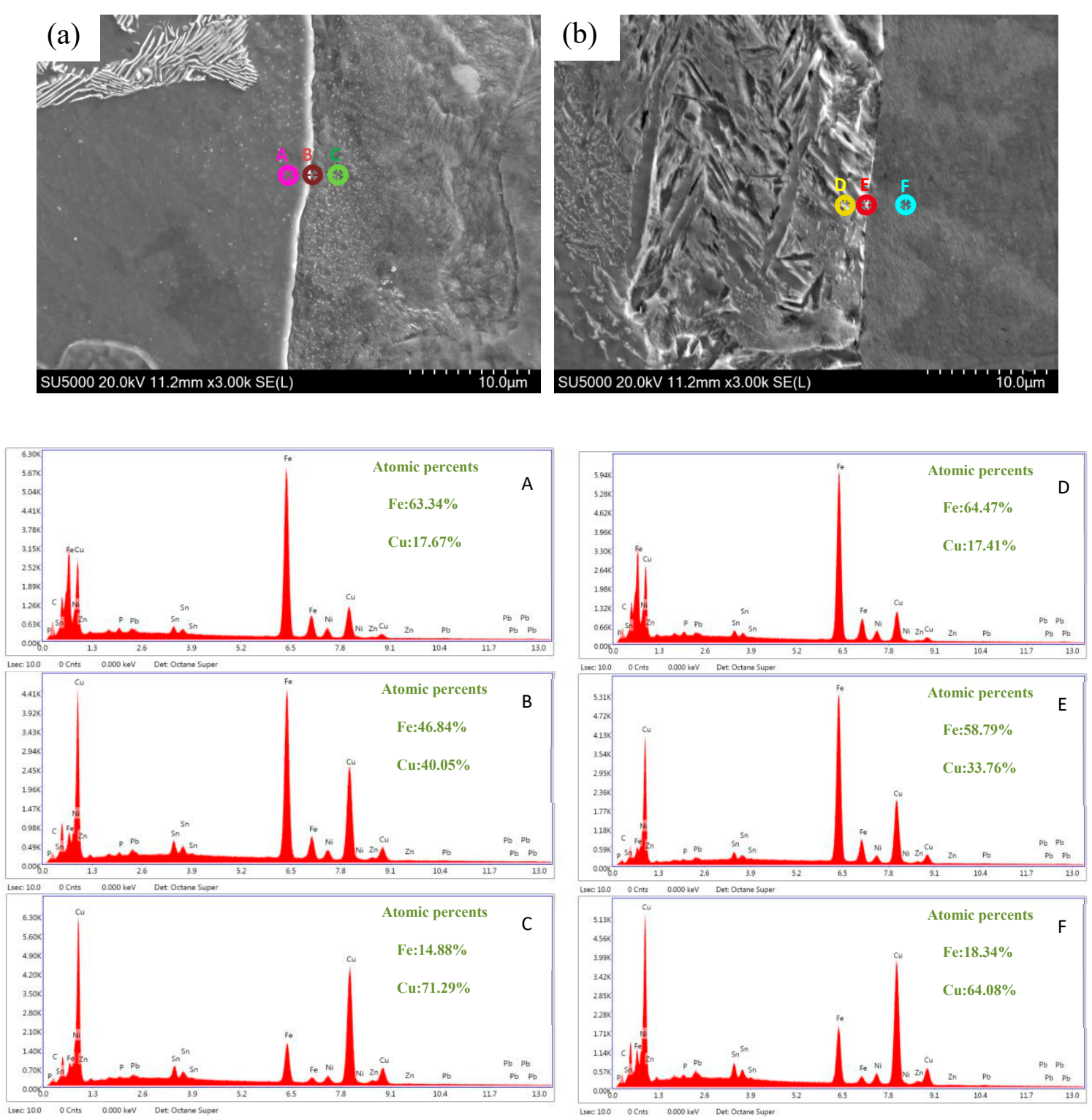

Figure 7. SEM micrograph and EDS analysis of the steel/copper bimetallic interface: (a) pearlite/copper interface and (b) ferrite/copper interface. 
To investigate the different diffusion behaviours of the pearlite and the ferrite, an EDS line analysis was performed throughout the steel/copper interface, as shown in Figure 8. From the EDS analysis result shown in Figure 8, we inferred that the white-bright diffusion layer was mainly composed of $\mathrm{Fe}$, and the grey part was composed of $\mathrm{Cu}$. In Figure 8, line (a) and line (b) illustrate the diffusion thicknesses of the copper atoms in the ferrite and the pearlite, respectively. Moreover, the selection of the diffusion distance was confirmed when the diffusion layer was formed until the percentage content exceeded $5 \%$ for one atom in another. Therefore, the diffusion distance between the copper atoms and the ferrite was significantly larger than that between the copper atoms and the pearlite, as inferred from line (a) and line (b).
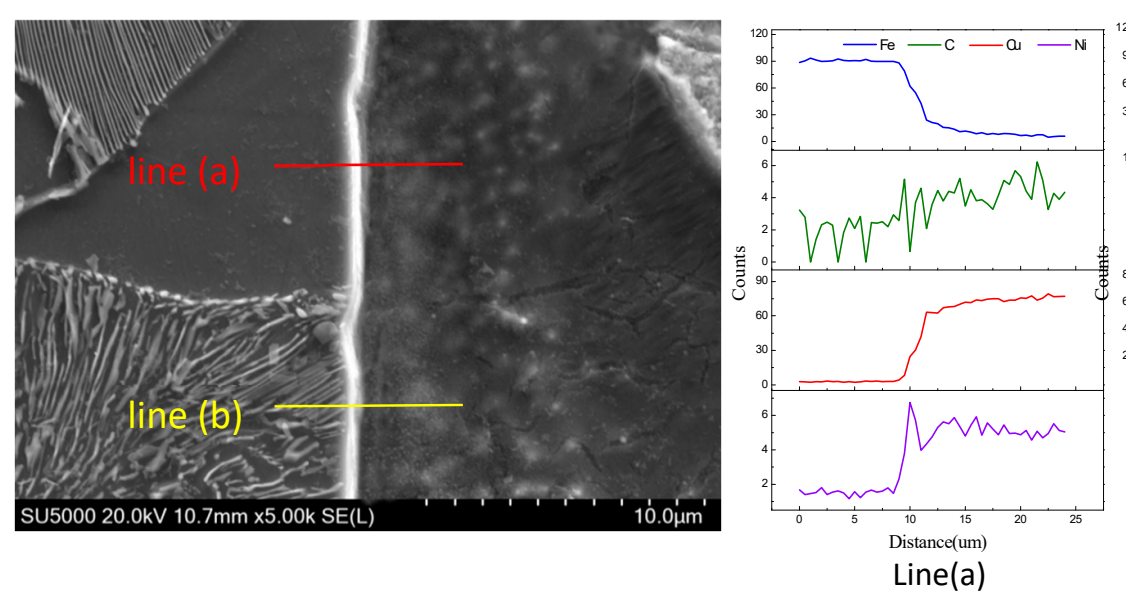

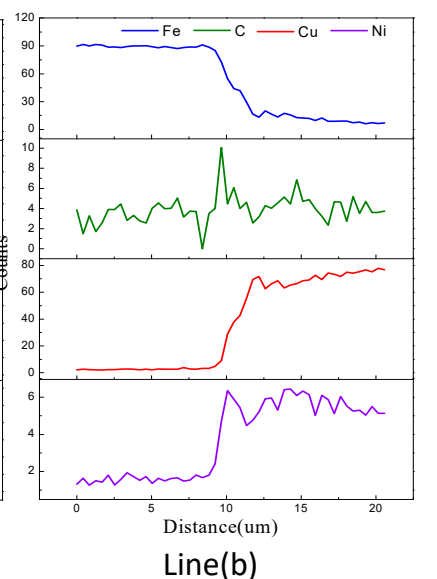

Line(b)

Figure 8. EDS line scan analysis of the $45 \mathrm{steel} /$ copper bimetallic interface.

From the EDS line analysis and statistics, the diffusion distance between the steel structure and the copper atoms were obtained, as shown in Figure 8. The diffusion distance of the ferrite/copper and the pearlite/copper interface increased with an increase in the carbon content of the steel matrix. Simultaneously, the diffusion thickness of the ferrite/copper interface was larger than that of the pearlite/copper interface under the same conditions, which indicated that the copper atoms diffused in ferrite faster than in pearlite, and the increased content of ferrite in the steel matrix improved the diffusion distance of the copper atoms. However, the appearance of cementite in the T8 steel, resulting in a slight decrease in the diffusion distance, might be attributed to the relatively poor diffusivity of the copper atoms in the cementite.

In general, the higher diffusion thickness represents the higher interface shear strength when the matrix contains a single organisational structure. However, it exhibited two different organisational structures and properties in this study because of the carbon steel in the pearlite and the ferrite. A comparison of Figures 4 and 9 reveals that the shear strength of the ferrite/copper interface was smaller than that of the pearlite/copper interface. However, the shear strength of the steel and copper bimetals needs a comprehensive consideration of the diffusion distance and bonding strength of the pearlite and ferrite with the copper alloy. Therefore, the diffusion distance of the 45 steel was smaller and the shear strength still remained high under the same casting conditions, which led to an excellent comprehensive performance. 


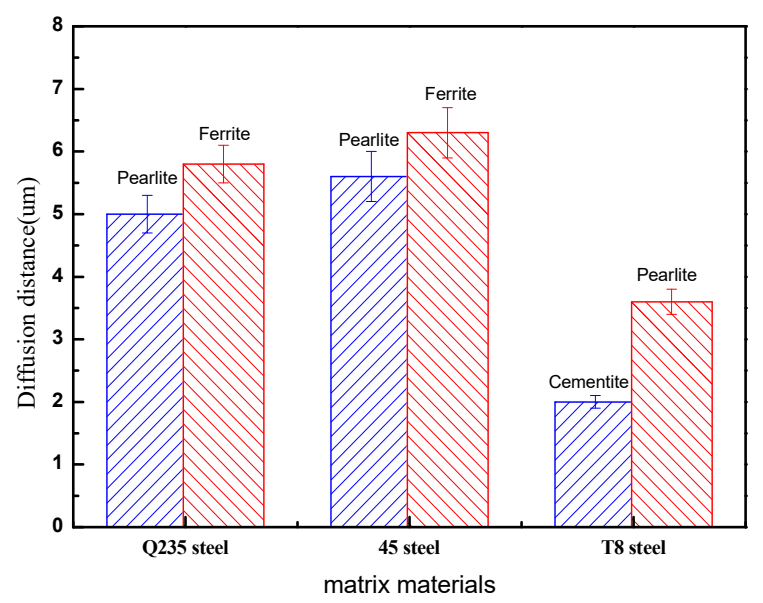

Figure 9. Thicknesses of the diffusion layer of the steel/copper bimetallic castings obtained with different structures of the carbon steel.

\subsection{Microhardness Characterisation}

The Vickers micro-hardness in the middle interface of the steel/copper bimetals with different steel substrates is shown in Figure 10. Note that the Vickers micro-hardness distributions of the steel/copper bimetallic composites with different steel substrates exhibited the same trend. As anticipated, the different steel substrates led to different micro-hardness values of the steel/copper bimetallic composites, and the Q235 steel at the interface had a lower hardness than the 45 steel and the T8 steel. However, the relative range of the micro-hardness of the Q235 steel/copper bimetal was wider than that of the 45 steel and the T8 steel, which was confirmed in the example of the $45 \mathrm{steel} /$ copper composite. Simultaneously, we observed that the diffusion distance of the Fe atoms was larger than that of the $\mathrm{Cu}$ atoms irrespective of the steel; this agreed well with the result presented in Section 3.2 and shown in Figure 5c.
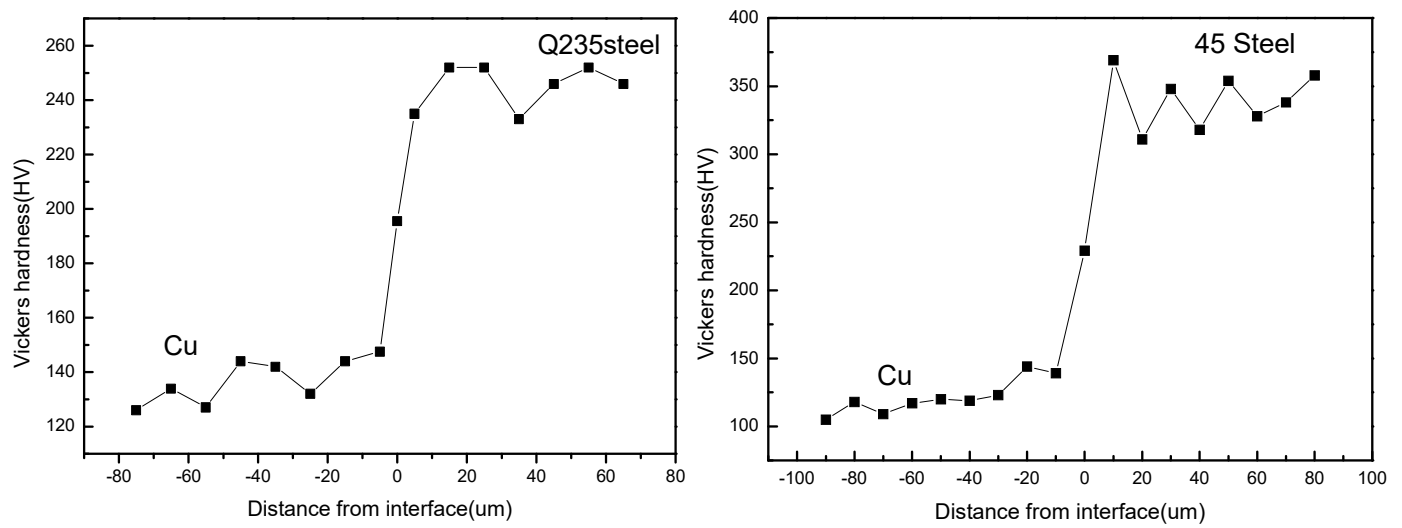

Figure 10. Micro-hardness profiles across the interfaces of the steel/copper bimetals.

For the 45 steel/copper bimetallic samples, as exhibited in Figure 11, showing the Vickers hardness of the ferrite/copper and the pearlite/copper interfaces, the hardness occurring on both sides of the interface changed from a uniform value gradually, which implied that the hardness of the steel matrix decreased and that of the copper alloy increased. Moreover, the interface hardness of steel and copper presented a gradually increasing trend with the growing pearlite in the steel matrix, indicating that the pearlite with the higher hardness contained copper atoms and the ferrite with the lower hardness contained copper atoms, as shown in Figure 11. The above figure of the diffusion distance shows that the diffusion distance of the steel/copper composite decreased with an increase in the pearlite. All these 
results indicated that the diffusion interface of the steel/copper was the result of the diffusion distance and the interface structure of the steel/copper bimetal composite.
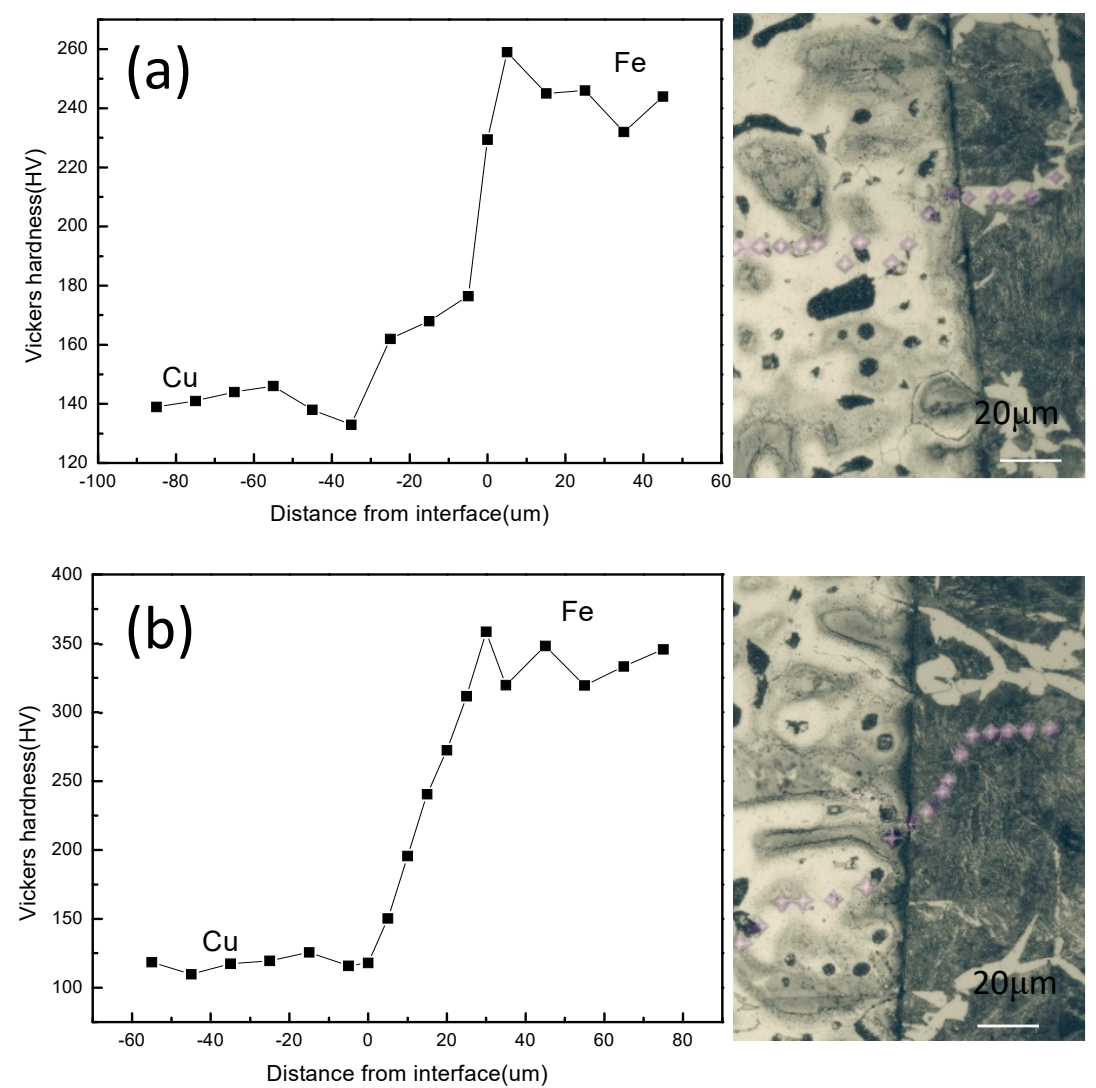

Figure 11. Micro-hardness and test indentations at the interfaces of the steel/copper bimetals:

(a) ferrite/copper interface and (b) pearlite/copper interface.

\subsection{Discussion}

The diffusion width of the ferrite/copper interface was thicker than that of the pearlite/copper interface, which indicated that the diffusion coefficient of copper atoms in ferrite was higher than that in pearlite. According to Fick's second law of diffusion [47], the diffusion coefficient increases with an increase in the temperature, and the diffusion distance increases with an increase in the diffusion time. However, the diffusion distance is not the only factor; the steel structure is also a determining factor affecting the bonding strength of the steel/copper bimetallic compound. Meanwhile, the different diffusion coefficients in the ferrite and the pearlite also determine the diffusion distance and bonding strength.

The casting status of the diffusion mechanism of the steel/copper bimetal composites with different steel types can be explained using diffusion. As shown in Figure 12a, the interlayer original state of the steel/copper alloy interface was obtained using the rapid induction heating solid-liquid bonding process. Furthermore, the copper atoms diffused in the ferrite and the pearlite regions of the Q235 steel, as shown in Figure 12b. The copper atoms mainly distributed in the ferrite region, and the diffusion distance was longer than that in the pearlite region because of the higher ratio in the Q235 steel. With the ratio decreases in the ferrite and pearlite, such as the 45 steel, the quantity of copper atoms passing through the interface exhibited the same trend, as shown in Figure 12c. However, with the continuous increase in the carbon content of the steel, the presence of cementite at the T8 steel hindered the diffusion of the copper atoms. At the same time, the pearlite content increased sharply with the ferrite content decreasing to zero, resulting in the lower diffusion distance and bonding strength. Therefore, in this work, we considered both the diffusion distance and the bonding strength 
in the fabrication of the steel/copper bimetallic composite, resulting in an excellent bonding interface between the copper and steel.
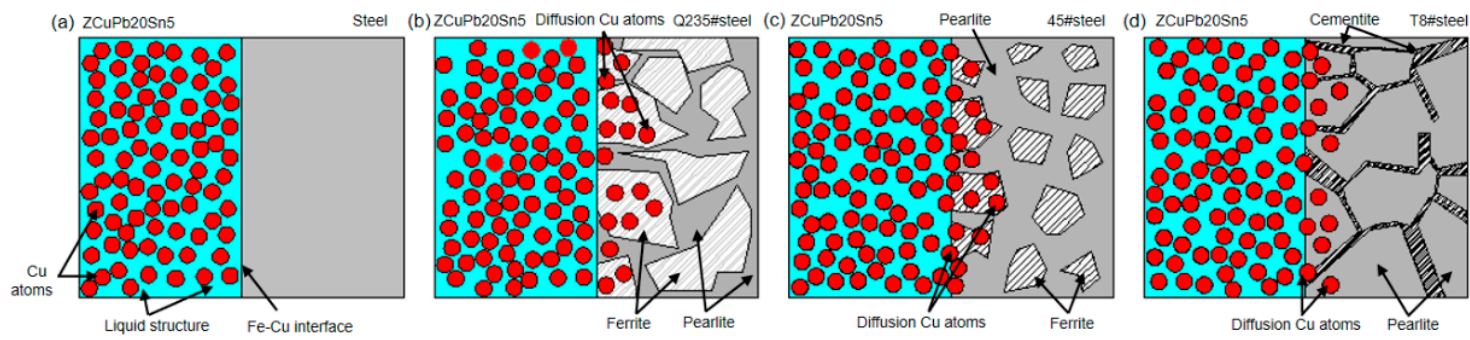

Figure 12. Diffusion mechanism of the interface of the carbon steel/copper bimetallic composites obtained using rapid induction heating: (a) interface before pouring, (b) interface of the Q235 steel and ZCuPb20Sn5, (c) interface of the 45 steel and ZCuPb20Sn5, and (d) interface of the T85 steel and $\mathrm{ZCuPb} 20 \mathrm{Sn} 5$.

\section{Conclusions}

In this study, the diffusion behaviour of steel/ZCuPb20Sn 5 bimetals was investigated using both experiments and molecular dynamics simulations. The main conclusions drawn were as follows:

- The pouring temperature and hold time had a considerable influence on the steel/copper bimetallic interface. A high bond strength bimetal was obtained at the pouring temperature of $1250{ }^{\circ} \mathrm{C}$ and the holding time of $40 \mathrm{~min}$;

- The steel/copper bimetals were successfully fabricated by the rapid induction heating of a solid-liquid compound. The 45 steel/copper bimetal had the highest bonding strength of $177 \mathrm{MPa}$ compared with the Q235 steel and T8 steel. The interface of the steel/copper exhibited preferable bonding and diffusion characteristics;

- The thicknesses of the diffusion distance of the copper atoms in ferrite, pearlite, and cementite were ranked in the following descending order: ferrite $>$ pearlite $>$ cementite. The order of the micro-hardness was the opposite;

- The diffusion distance of the copper atoms in the carbon steel matrix was smaller than that of the iron atoms in the ZCuPb20Sn5 matrix. The microstructure and the mechanical properties of the steel played an important role in the fabrication of the steel/copper bimetals with a higher bonding strength;

- The simulation results revealed that the diffusion coefficient of the $\mathrm{Cu}$ atoms at $1523 \mathrm{~K}$ was larger than that of the Fe atoms, but the diffusion distance of the Fe atoms in the $\mathrm{Cu}$ bulk was larger than that of the $\mathrm{Cu}$ atoms in the Fe bulk. These results agreed very well with the experimental results.

Author Contributions: Funding acquisition, G.Z.; conceived and designed the experiments, H.X.; carried out the experiments and data collection, M.W. and Y.Z.; writing—original draft preparation and review, M.W.; All authors have read and agreed to the published version of the manuscript.

Funding: This work is supported by the Natural Science Foundation of Shanxi province (Nos.201801D121111), the Natural Science Foundation of Shanxi province (No.201801D121108).

Conflicts of Interest: Author M.W., G.Z., H.X. and Y.Z. has both received research grants from North university of china. We declare that we have no financial and personal relationships with other people or organizations that can inappropriately influence our work, the authors declare that they have no conflict of interest. 


\section{References}

1. Rhee, K.; Han, W.; Park, H.; Kim, S. Fabrication of aluminum/copper clad composite using hot hydrostatic extrusion process and its material characteristics. Mater. Sci. Eng. A 2004, 384, 70-76. [CrossRef]

2. Lee, J.; Bae, D.; Chung, W.; Kim, K.; Lee, J.; Cho, Y.-R. Effects of annealing on the mechanical and interface properties of stainless steel/aluminum/copper clad-metal sheets. J. Mater. Process. Technol. 2007, 187, 546-549. [CrossRef]

3. Gao, H.; Wang, J.; Sun, B. Effect of Ag on the thermal stability of deformation processed Cu-Fe in situ composites. J. Alloy. Compd. 2009, 469, 580-586. [CrossRef]

4. Ko, C.; Lee, K.; Kim, M.; Jo, H.; Jo, H. Evaluation of copper coating ratio in steel/copper clad wire drawing. J. Mater. Process. Technol. 2008, 186, 22-26. [CrossRef]

5. Sarkar, T.; Bose, P.; Sutradhar, G. Mechanical and tribological characteristics of copper alloyed austempered gray cast iron (AGI). Mater. Today Proc. 2018, 5, 3664-3673. [CrossRef]

6. Abbas, S.F.; Seo, S.-J.; Park, K.-T.; Kim, B.S.; Kim, T.-S. Effect of grain size on the electrical conductivity of copper-iron alloys. J. Alloy. Compd. 2017, 720, 8-16. [CrossRef]

7. Tong, B.; Yang, W.; Liu, Q.; Ye, X.; Shi, L. Flowing and pressure-balancing characteristics of clearance field in helical grooved piston-copper sleeve pair of piston pump. Trans. Chin. Soc. Agric. Eng. 2018, 34, 55-63.

8. Ramprabhu, T.; Sriram, S.S.; Boopathy, K.; Narasimhan, K.; Ramamurty, U. Effect of copper addition on the fatigue life of low alloy C-Mo powder metallurgy steel. Met. Powder Rep. 2011, 66, 28-34. [CrossRef]

9. Silman, H.; Fry, M.F.E. The lead plating of bronze bearing surfaces for high pressure fuel pumps. Trans. IMF 1947, 23, 43-58. [CrossRef]

10. Zou, J.; Li, S.; Wei, Y.; Liang, S. Research of the bonded interface of Cu9A14Fe/1Cr18Ni9Ti stainless steel bimetallic composite. Vacuum 2017, 146, 266-273. [CrossRef]

11. Hiroe, T.; Fujiwara, K.; Hata, H.; Takahashi, H. Deformation and fragmentation behaviour of exploded metal cylinders and the effects of wall materials, configuration, explosive energy and initiated locations. Int. J. Impact Eng. 2008, 35, 1578-1586. [CrossRef]

12. Barlas, Z. Weldability of CuZn30 brass/DP600 steel couple by friction stir spot welding. Acta Phys. Pol. A 2017, 132, 991-993. [CrossRef]

13. Kershenb, V.Y. Performance of steel-bronze bimetal produced by friction surfacing. Weld. Prod. 1972, $19,48-50$.

14. Mai, T.; Spowage, A. Characterisation of dissimilar joints in laser welding of steel-kovar, copper-steel and copper-aluminium. Mater. Sci. Eng. A 2004, 374, 224-233. [CrossRef]

15. Yao, C.; Xu, B.; Zhang, X.; Huang, J.; Fu, J.; Wu, Y. Interface microstructure and mechanical properties of laser welding copper-steel dissimilar joint. Opt. Lasers Eng. 2009, 47, 807-814. [CrossRef]

16. Liu, Y.; Wang, Y.; Chen, W. Sintering procedure and properties of mining used bimetal shaft sleeve. Dev. Appl. Mater. 2004, 1, 24-26.

17. Liu, R.-T.; Xiong, X.; Chen, F.-S.; Lu, J.; Hong, L.-L.; Zhang, Y.-Q. Tribological performance of graphite containing tin lead bronze-steel bimetal under reciprocal sliding test. Tribol. Int. 2011, 44, 101-105. [CrossRef]

18. Yin, Y.; Tang, H.; Jiao, M.; Zhang, G.; Xue, L.; Tian, M. Tribological performance of lead-free Ni-contained copper-steel bimetal bearing materials. Chin. J. Nonferr. Met. 2017, 27, 1189-1198.

19. Zhang, P.; Du, Y.; Liu, H.; Zeng, D.; Ba, L. The influence of preheat temperature of steel plate on steel-mushy Cu-graphite bonding. J. Wuhan Univ. Technol. Sci. Ed. 2006, 21, 12-14. [CrossRef]

20. Tang, J.D.; Li, L.M.; Zhu, Z.F. Research of Induction Heating and Particle Centrifugal Melting Technique for Steel-backed Copper Lead Alloy Sliding Bearing. Locomot. Roll. Stock Technol. 2012, 5, 1-3.

21. Du, Y.H.; Zhang, P.; Liu, H.W.; Zeng, D.B. Optimization of steel-mushy Cu-graphite press bonding. J. Tsinghua Univ. (Sci. Technol.) 2013, 2, 4-8.

22. Luozzo, N.D.; Boudard, M.; Fontana, M.; Arcondo, B. Effective diffusion coefficient for Cu in steel joined by transient liquid phase bonding. Mater. Des. 2016, 92, 760-766. [CrossRef]

23. Gale, W.F.; Butts, D.A. Transient liquid phase bonding. Sci. Technol. Weld. Join. 2004, 9, 283-300. [CrossRef]

24. Zhang, G.; Zhang, J.X.; Pei, Y.; Niu, J. Properties of the joint bonded by transformation/diffusion brazing and diffusion behaviours of the major elements. Acta Metall. Sin. 2004, 40, 653-658. 
25. Meitei, R.K.B.; Maji, P.; Samadhiya, A.; Ghosh, S.K.; Roy, B.S.; Das, A.K.; Saha, S.C. A study on induction welding of mild steel and copper with flux under applied load condition. J. Manuf. Process. 2018, 34, 435-441. [CrossRef]

26. Baglyuk, G.A.; Sosnovskii, L.A.; Volfman, V.I. Effect of carbon content on the properties of sintered steels doped with manganese and copper. Powder Met. Met. Ceram. 2011, 50, 189-193. [CrossRef]

27. Gosh, R.C.; Syed, I.M.; Amina, Z.; Bhuiyan, G.M. A comparative study on temperature dependent diffusion coeffcient of liquid Fe. Phys. B Condens. Matter 2013, 426, 127-131. [CrossRef]

28. Guo, M.H.; Enomoto, C.J. Simulation of bcc-Cu precipitation in ternary Fe-Cu-Mn alloys. Comput. Mater. Sci. 2018, 141, 101-113. [CrossRef]

29. Shang, S.-L.; Zhou, B.-C.; Wang, W.Y.; Ross, A.J.; Liu, X.; Hu, Y.-J.; Fang, H.-Z.; Wang, Y.; Liu, Z.-K. A comprehensive first-principles study of pure elements: Vacancy formation and migration energies and self-diffusion coefficients. Acta Mater. 2016, 109, 128-141. [CrossRef]

30. Prokoshkina, D.; Esin, V.; Divinski, S.V. Experimental evidence for anomalous grain boundary diffusion of Fe in Cu and Cu-Fe alloys. Acta Mater. 2017, 133, 240-246. [CrossRef]

31. Liu, T.; Wang, Q.; Sui, Y.; Wang, Q.; Ding, W. An investigation into interface formation and mechanical properties of aluminum-copper bimetal by squeeze casting. Mater. Des. 2016, 89, 1137-1146. [CrossRef]

32. Sun, C.; Li, L.; Fu, M.; Zhou, Q. Element diffusion model of bimetallic hot deformation in metallurgical bonding process. Mater. Des. 2016, 94, 433-443. [CrossRef]

33. Tavassoli, S.; Abbasi, M.; Tahavvori, R. Controlling of IMCs layers formation sequence, bond strength and electrical resistance in Al Cu bimetal compound casting process. Mater. Des. 2016, 108, 343-353. [CrossRef]

34. Jiang, W.; Fan, Z.; Li, C. Improved steel/aluminum bonding in bimetallic castings by a compound casting process. J. Mater. Process. Technol. 2015, 226, 25-31. [CrossRef]

35. Plimpton, S. Fast Parallel Algorithms for Short-Range Molecular Dynamics. J. Comput. Phys. 1995, 117, 1-19. [CrossRef]

36. Bonny, G.; Pasianot, R.; Castin, N.; Malerba, L. Ternary Fe-Cu-Ni many-body potential to model reactor pressure vessel steels: First validation by simulated thermal annealing. Philos. Mag. 2009, 89, 3531-3546. [CrossRef]

37. Zhang, T.-T.; Xie, R.; Wang, W.; Zhou, J.; Cao, X.; Wei, Y. Molecular dynamics simulations and experimental investigations of atomic diffusion behavior at bonding interface in an explosively welded $\mathrm{Al} / \mathrm{Mg}$ alloy composite plate. Acta Met. Sin. Engl. Lett. 2017, 30, 983-991. [CrossRef]

38. Guo, Q.; Greer, J.R. Compressive properties of interface-containing Cu-Fe nano-pillars. Scr. Mater. 2011, 66, 272-275. [CrossRef]

39. Edstrom, D.; SanGiovanni, D.; Hultman, L.; Petrov, I.; Greene, J.; Chirita, V. Effects of incident N atom kinetic energy on TiN/TiN(001) film growth dynamics: A molecular dynamics investigation. J. Appl. Phys. 2017, 121, 025302. [CrossRef]

40. Edström, D.; SanGiovanni, D.; Hultman, L.; Chirita, V.; Petrov, I.; Greene, J. Ti and N adatom descent pathways to the terrace from atop two-dimensional TiN/TiN(001) islands. Thin Solid Films 2014, 558, 37-46. [CrossRef]

41. Ko, W.-S.; Grabowski, B.; Neugebauer, J. Development and application of a Ni-Ti interatomic potential with high predictive accuracy of the martensitic phase transition. Phys. Rev. B 2015, 92. [CrossRef]

42. Maisel, S.B.; Ko, W.-S.; Zhang, J.-L.; Grabowski, B.; Neugebauer, J. Thermomechanical response of NiTi shape-memory nanoprecipitates in TiV alloys. Phys. Rev. Mater. 2017, 1. [CrossRef]

43. SanGiovanni, D.; Mei, A.B.; Edstrom, D.; Hultman, L.; Chirita, V.; Petrov, I.; Greene, J. Effects of surface vibrations on interlayer mass transport: Ab initio molecular dynamics investigation of Ti adatom descent pathways and rates from TiN/TiN (001) islands. Phys. Rev. B 2018, 97, 035406. [CrossRef]

44. SanGiovanni, D.; Edstrom, D.; Hultman, L.; Petrov, I.; Greene, J.; Chirita, V. Ti adatom diffusion on TiN(001): $\mathrm{Ab}$ initio and classical molecular dynamics simulations. Surf. Sci. 2014, 627, 34-41. [CrossRef]

45. Almyras, G.A.; Sangiovanni, D.G.; Sarakinos, K. Semi-Empirical Force-Field Model for the $\operatorname{Ti}_{1-x} \mathrm{Al}_{x} \mathrm{~N}$ $(0 \leq x \leq 1)$ System. Materials 2019, 12, 215. [CrossRef] [PubMed] 
46. Zhang, J.; Xiao, Y.; Luo, G.; Shen, Q.; Zhang, L. Effect of Ni interlayer on strength and microstructure of diffusion-bonded Mo/Cu joints. Mater. Lett. 2012, 66, 113-116. [CrossRef]

47. Bu, H.; Yandouzi, M.; Lu, C.; Jodoin, B. Effect of heat treatment on the intermetallic layer of cold sprayed aluminum coatings on magnesium alloy. Surf. Coat. Technol. 2011, 205, 4665-4671. [CrossRef]

(C) 2020 by the authors. Licensee MDPI, Basel, Switzerland. This article is an open access article distributed under the terms and conditions of the Creative Commons Attribution (CC BY) license (http://creativecommons.org/licenses/by/4.0/). 